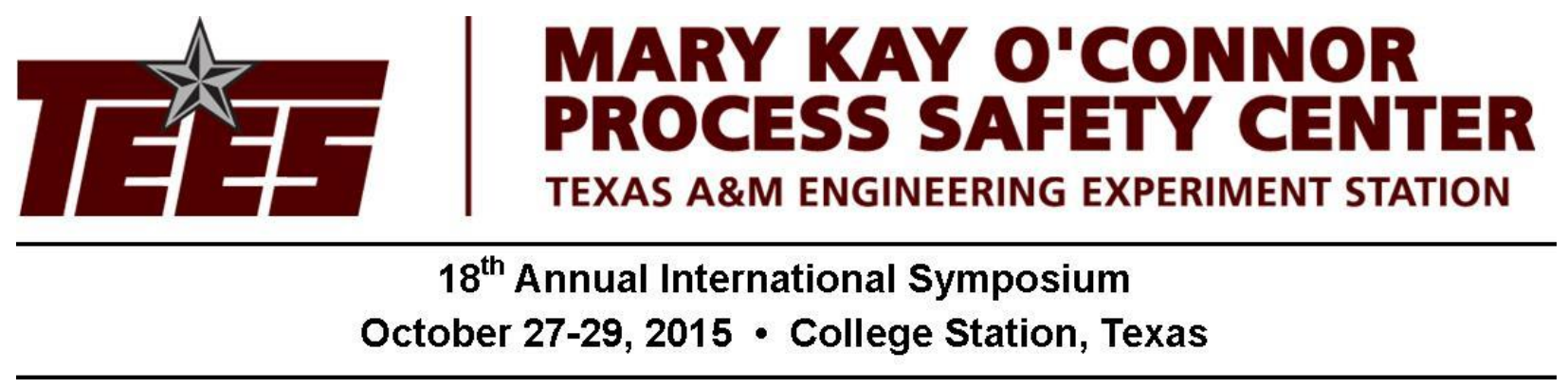

\title{
Explosion Loading on Equipment from CFD Simulations
}

\author{
Olav R. Hansen ${ }^{1}$, Malte T. Kjellander ${ }^{1}$, and Jan A.Pappas ${ }^{2}$ \\ ${ }^{1}$ Lloyd's Register Consulting, Bergen, Norway, Email: olav.hansen@lr.org \\ ${ }^{2}$ Lloyd's Register Consulting, Sandvika, Norway
}

\begin{abstract}
:
Explosion studies using computational fluid dynamics (CFD) are performed on daily basis among safety consultants all over the world. The purpose of the explosion studies is usually to give guidance on required design strength of equipment, piping, blast walls or buildings. One key element is to translate the results from an explosion simulation, into actual forces on equipment. Major weaknesses exist in the current approaches for estimation of loads on small and medium sized equipment. Hansen et al. (2014) demonstrated how loads on rectangular equipment could be estimated by combining free field form drag and pressure gradient. In the current work it is discussed how best to estimate loads onto other types of equipment including cylindrical pipes, pipe bundles and other shapes, and some comparisons and validation against large scale experiments are also included. The main findings of this work are the more accurate guidance on how best to extract explosion loads from simulations, including discussons on appropriate drag coefficients.
\end{abstract}

\section{$1 \quad$ Introduction}

Explosion studies are performed to give guidance on required design strength or to confirm actual design for a facility or nearby structures. For offshore oil and gas installations a common approach (NORSOK Z-013, 2010, and ISO 19901-3, 2010) is to demonstrate that the nontolerable explosion that will give uncontrolled escalation/damage has a return frequency lower than e.g. $10^{-4} /$ year, and when possible robustness against even less frequent high consequence scenarios should be demonstrated. Another common approach is to design to withstand a worstcase credible explosion (API RP-752, 2009). For most studies on offshore petrochemical installations, and also frequently for onshore facilities, Computational Fluid Dynamics (CFD) simulations with FLACS are performed to predict the nature of the explosion loads of concern (Hansen et al., 1999 and Hansen et al., 2013).

In a transient flow field during an explosion pressure differences will build up around objects, and by integrating the pressure over the surface of an object, the explosion loading (forces onto 
the object) can be obtained. For objects properly resolved on the simulation grid in a CFDsimulation, like blast walls, decks and large objects with a minimum of 2-3 grid cells across, explosion loads can be well estimated from differential pressures. Typical grid cell size for explosion studies at a petrochemical facility is $0.5 \mathrm{~m}$ to $1.0 \mathrm{~m}$. For smaller objects estimates of differential pressures will be less accurate, and may not be possible to extract if diameter is less than 1.0-1.5 grid cells. For such objects the load may be estimated from a general drag formula (Sand, 1999):

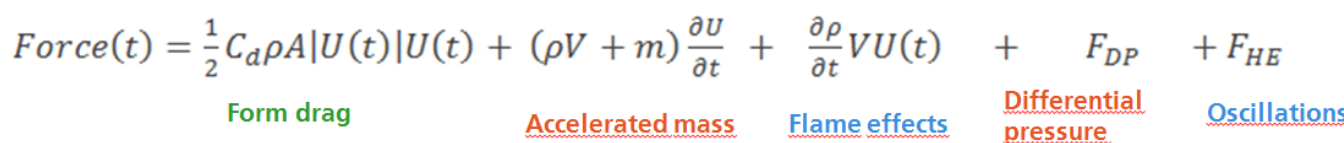

The first term is the form drag, the second term is primarily accelerated mass, third term is forces due to density changes during combustion, fourth term is from pressure waves in the flow field and the last term is a hydro-elastic term potentially increasing the drag force due to oscillations.

Load estimates for pipes and smaller equipment are usually only considering the form drag, with increasing size of object the second (accelerated mass) and fourth terms (pressure waves) of equation (1) become more important.

The guidance from (FABIG TN-08) on how to estimate loads on objects based on CFDexplosion calculations is as follows:

Object size: $\quad$ Proposed method to estimate loads:

Diameter $>2 m \quad$ Direct load measurement (DLM) to report pressure on surfaces $(P D F=$ pressure distribution factor used if maximum local $\square P$ is used $)$ :

$$
F=\square P \cdot A \cdot P D F \quad P D F=1.0(\text { box }) \text { or } 2 / \square=0.64 \text { (cylinder) }
$$

Diameter $<0.3 m \quad$ Use form drag formula with conservative drag coefficients from (Baker, 1983)

$$
F=\square \square \cdot v^{2} \cdot C_{d} \cdot A \quad C_{d}=2.0(\text { box }) \text { or } 1.2(\text { cylinder })
$$

$0.3 m<D<2.0 m \quad$ Form drag formula for objects up to D 0.5-1.0m, no suggestion for 1.0$2.0 m$.

The Lloyd's Register Guidance Notes for the Calculation of Probabilistic Explosion Loads (Lloyd's Register, 2015) suggest 3 alternative methods for load estimation for objects $0.3 \mathrm{~m}$ to $2.0 \mathrm{~m}$, these are:

a) local grid refinement and use of DLM

b) estimation methods including load contributions 2 and 4 of the net reaction force (1)

c) interpolation between loads on objects resolved on the grid (DLM) and drag load

Due to the Cartesian grid of FLACS a grid refinement around a target will in most cases have implication on the grid size/shape and the time step settings, which can change the predicted 
explosion loads significantly. Expert users can limit the impact of local grid refinement by instructing the time stepping routines of FLACS to ignore local grid refinement. Still, this method should be used with care and primarily for one or a few simulations only.

(Hansen et al., 2014) described estimation methods including load contributions from accelerated mass and pressure waves and demonstrated the ability to predict directional, transient loads onto various box shaped objects from weak and strong explosions with good precision using the formula:

$$
\text { Force }(t) / \text { Area }=C_{d} x \text { Drag }(t)+\operatorname{PDF} x\left[P_{s}(t)-P_{s}(t-\square t)\right]
$$

With Drag $=1 / 2 \square \mathrm{u}^{2}$ and $\mathrm{P}_{\mathrm{s}}$ being the static (side-on) pressure in the flowfield near the object. $\square \mathrm{t}$ is the estimated time for the pressure waves to equalize around the object, which is estimated based on the size and shape of the object and the fluid temperature $\left(\mathrm{C}_{\text {sound }} \sim \mathrm{T}^{-1 / 2}\right.$, i.e. $\square \mathrm{t}$ is almost 3 times higher prior to flame arrival than after). $\mathrm{PDF}$ is a pressure distribution factor ( $\mathrm{PDF}=1.0$ for box shapes, $\mathrm{PDF}=2 / \square=0.64$ for cylinders). In Figure 1 this method is illustrated for a $1 \mathrm{~m}$ box shaped target $43 \mathrm{~m}$ outside an explosion with the drag (blue dotted curve) and side-on pressure (red dotted curve) used to estimate the force on the object (black solid curve is estimate, black dotted curve is actual load from DLM). This is illustrating a frequent challenge in explosion studies, where reported drag loads and pressure loads are to be used to estimate loads on e.g. lifeboats, crane supports and other critical equipment outside the explosions. From Figure 1 it should be obvious that neither the drag nor the pressure loads are representative for the actual load as both the magnitudes and durations are very wrong. Using relation (2), however, the transient load curve, including magnitude and duration, is estimated with good precision.

The $3^{\text {rd }}$ method, interpolation, has been used frequently in the past. One challenge with the method is that while there may be reported drag values all over the domain, there may only be a few larger objects which can be used to report DLMs, and it is not obvious that an estimated load on a $1.5 \mathrm{~m}$ diameter object will be particularly accurate if this is based on interpolation between a local drag value and a direct load measurement on the nearest $4 \mathrm{~m}$ sized object that could be $20 \mathrm{~m}$ away. As a consequence in studies performed by Lloyd's Register Consulting in recent years, reported pressures on local wall and deck panels $(3 \mathrm{~m} \times 3 \mathrm{~m})$ spread all over the modules, have been used for the interpolation as an estimate for local DLM across medium sized objects. 


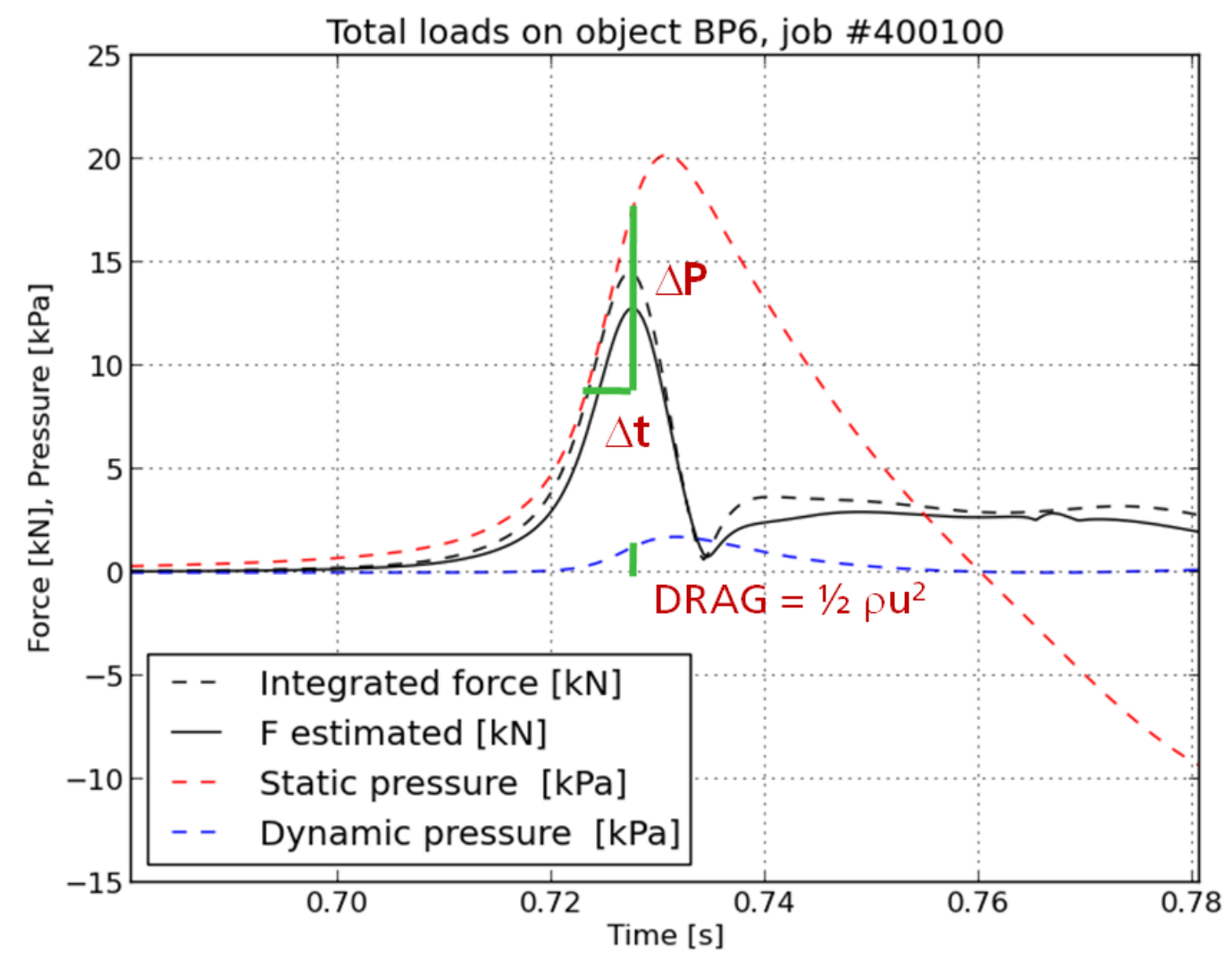

Figure 1 Improved method for load estimation from explosions, the pressure load (black curves - dotted=actual, solid=estimated) on an object equals the dynamic pressure $x$ drag coefficient (blue curve $x$ Cd) plus $\square \mathbf{P}$ (pressure change in time $\square t$, red curve)

The character of explosion loading will vary significantly with explosion strength, and whether the target is inside or near the explosion, or in the far-field. Inside the explosion the duration of the loads will often be rather long, often 100-200 ms, similar to the duration of the local pressure peak, and a triangular approximation of the load with $\mathrm{T}_{\text {duration }}=2 \mathrm{x} \mathrm{T}_{\text {risetime }}$ can often be representative. Some distance outside the explosion the loads may be dominated by pressure waves, usually shockwaves from explosions $\sim 0.5$ bar and higher, and the duration of the load onto a $1-2 \mathrm{~m}$ sized object tends to be signficantly shorter, typically around 5-15 ms while the blast wave itself may have a duration of $20-40 \mathrm{~ms}$.

Chapter 2 will highlight important elements of the modelling that must be right before proper explosion loads can be predicted. Chapter 3 will go through how best to extract loads from explosion simulations for different types of equipment. Chapter 4 will discuss proper drag coefficients, and include a validation example from BFETS full scale tests, while Chapter 5 and Chapter 6 will discuss elements around the application of explosion loads in design. 
Before accurate estimates of explosion loads can be extracted it is important that the competent modeller uses a properly validated CFD model, following the best practice user guidelines, and models relevant and representative scenarios.

A competent modeller should know the CFD tool very well, be aware of limitations and validity, and follow relevant user guidelines. It is also important that the modeller understands well the phenomena being modelled, as well as the study philosophy/approach of the explosion study.

For gas explosion modelling FLACS is with little doubt the best validated and globally most used CFD model towards the petrochemical industry. The FLACS development from 1982 until 2000 at CMI/CMR was primarily done with support from major oil and gas industry through joint industry projects. The development teams were thereafter transferred to GexCon which has continued the development with license maintenance payments from commercial users being the main funding. Validation against experiments has been a key activity in the FLACS development, see e.g. (Hansen et al. 1999), and best practice user guidelines have been established based on this.

Best practice user guidelines for FLACS include several different topics, and much of this can be found in the user manual (GexCon, 2015), but useful information is to be found also in e.g. (NORSOK Z-013, 2010) and (Lloyd's Register, 2015). The most important topics for explosion loading may be:

- Accurate 3D geometry model is required, with proper confinement (walls, decks, vent areas) and a representative congestion level, i.e. as much as possible details of piping and equipment included, and with fine piping and equipment added as anticipated congestion (AC) to obtain expected reference levels of congestion (pipelength/volume and area/volume). With the FLACS interfaces selected geometry elements from other as-built geometry models, can be efficiently copied and manipulated to develop realistic AC.

- Grid guidelines must be followed strictly in particular the requirements for sufficient resolution with cubical grid cells of gas cloud/congested region (10-13 grid cells in shortest direction), and also proper grid resolution towards far-field targets (2-4 times coarser grid cells may be acceptable).

- Time resolution must be as specified in the FLACS guidelines during the flame acceleration and pressure generation $(\mathrm{CFLC}=5$ and $\mathrm{CFLV}=0.5)$. For strong explosions with source pressure higher than $0.5 \mathrm{barg}$, shock waves can be expected in the far-field. In order to avoid numerical smearing and underprediction of loads, Hansen and Johnson (2015) concluded that a finer time step must be used after the blast waves have separated from the flame front $(\mathrm{CFLC}=0.1)$. For weaker explosions standard time step settings can be kept, but time step control key "KEEP_LOW" must be specified to avoid increased time steps and blast smearing.

- Scenario parameters must also be defined accurately, including gas composition. If a Q9 equivalent stoichiometric volume is defined the gas concentration should be at slightly fuel-rich concentrations (ER 1.05). For far-field loading estimates it is essential to use the non-reflecting boundary condition "PLANE_WAVE". In most cases there will be 
some air movement and turbulence in the gas cloud, and some pre-ignition turbulence should be defined (Hansen et al. 2013, Lloyd's Register, 2015, NORSOK Z-013, 2010).

- The loading targets (walls, decks, equipment and other) should be properly instrumented with pressure panels or drag/pressure sensors appropriately placed, see discussion in following chapters.

Finally, when representative loads shall be predicted it is important that relevant scenarios are simulated and evaluated. If a worst-case or realistic worst-case approach is used, it is essential that the selected scenarios really do represent the worst events that may be expected, and as the distribution of explosion loads may be directional for a scenario, the worst-case scenarios for one target may be different from the worst-case scenario for another target. If a probabilistic assessment is performed, it is important that the distribution of scenarios is representative, with a proper distribution of cloud sizes, locations and ignition locations and frequencies.

FLACS is a deflagration model, but has functionality to predict if deflagration-to-detonation may take place, and with certain settings it may also be possible to predict the detonation consequences (Hansen and Johnson, 2015). Inside the exploding cloud, the consequences given DDT will usually be far too severe to design against, for far-field pressures outside the gas cloud, however, it may be of interest to predict the loads.

\section{How to extract loading on different types of targets}

In the following it will be discussed how loads can be extracted for various types of objects. The shape and duration of the overpressure pulses onto a target will depend strongly on where the target is located relative to the exploding gas cloud, and of course the character/strength of the explosion.

\section{Shape and duration of loads inside the flame region}

In a gas explosion (deflagration) the flame will normally start slowly, with initial flame speeds of the order 1 to $10 \mathrm{~m} / \mathrm{s}$. Depending on turbulence generation ahead of the flame, confinement, shape and reactivity of the flammable cloud, the flames may accelerate and flame speeds for explosions of relevance to structural strength will generally end up in the range $100-1000 \mathrm{~m} / \mathrm{s}$. During this acceleration process the overpressure will be increasing to a maximum, and thereafter fall to zero and below. The typical pressure curve shape inside the flame region can often be represented with an idealized triangular pulse with a rise time of 50-100 ms, and often a duration around twice the rise time, i.e. 100-200 ms. The underpressure following the initial pressure pulse may typically be around $20 \%$ of the maximum overpressure, and usually within the range 10-30\% for typical explosion scenarios with overpressures $0.25-2.0$ bar, with a duration comparable to the positive pressure pulse duration. Within an area there may be signficant variations in maximum overpressures, while the underpressure from the surge after the explosion may be more evenly distributed, which means that locations with a relatively low overpressure may see an underpressure as high, or even higher than the overpressure. The durations of all peaks, positive and negative, will generally be reduced when the strength of the explosion increases. 
The triangular pulse shape assumption may often be representative for pressure and drag loads inside the flame zone. From this simplified shape assumption there may be lots of deviations depending on the location the pressure is reported, in particular for increasing complexity in the gas cloud shape and the confining wall structures, there may be reflections and oscillations occurring, giving double and even triple positive peaks in the overpressure, which may be more questionable to represent with the simplified triangular profile.

For very strong explosion there is a possibility of DDT, and when this happens there will be a strong discontinuity (shock) in the pressure waves, with an immediate jump to 10-30 barg, and if there are significant unburnt pockets of gas remaining, these will likely detonate within the next few milliseconds. The load pattern will be dominated by extreme loads with zero rise time of pressure, and due to the very intense combustion in the flame front, the main drag loads will act backwards (and possibly sideways/upwards out of the flame) behind the flame.

With increasing confinement and gas clouds filling a significant fraction of the area, pulse durations can increase, and for the extreme with a strong, confined room or vessel filled with gas, it may be heat losses to walls that reduce the overpressure after the explosion and the duration of pressure may be of several seconds.

\section{Shape and duration of loads into the far-field}

Outside a surge region around the flame zone the explosion loads will gradually get the character of pressure waves. For explosions with source overpressures of the order 0.5 bar or higher, the pressure waves will tend gradually to develop into shockwaves with zero rise time, and with a typical duration around half compared to inside the flame zone, slightly increasing with distance. Underpressures may have comparable duration, but strength is often of the order 10 to $30 \%$ of the peak overpressures. For weaker source explosions the rise time can be long and the underpressure sometimes of comparable strength and duration as the positive pulse.

Within a large offshore module with partial confinement (e.g. deck, ceiling and one or more blast walls) in which the flame zone may be only a fraction of the module, the loads some distance away from the flame zone may have a character between what has been characterized as far-field and near-field loads, as the confining structures may still ensure that the flame surge (drag loads) is influencing the load pattern.

In Figure 2 some examples of typical flame zone and far-field pressures are shown to illustrate variations in pressure duration, overpressure distribution and shape and underpressure. All tests are performed at DNV GL test site Spadeadam. Some description of experiments and previous CFD modelling work can be found in Hansen et al. (2013) and Hansen and Johnson (2014).

The first test BFETS-7 is the end ignited explosion test with $1600 \mathrm{~m}^{3}$ stoichiometric natural gas mixture (100\% of tunnel shaped module), with maximum overpressures centrally in the module around 2 barg and duration more than $100 \mathrm{~ms}$, and above 4 barg with multiple peaks and 50-80 $\mathrm{ms}$ duration where the flames exit the module. Blast pressures shown $30 \mathrm{~m}$ and $50 \mathrm{~m}$ diagonally outside the end of the module have the character of shock waves with a duration around 25$30 \mathrm{~ms}$. 
The second example is from Phase 3B project and is the first of three $2600 \mathrm{~m}^{3}$ stoichiometric gas clouds base case reference tests with ignition near center of gas cloud and $12 \mathrm{~m} \times 8 \mathrm{~m}$ vent openings on three sides (North, East and West). Maximum explosion pressures above 4 barg were recorded near the East vent opening (maximum flame travel distance), and somewhat lower pressures 1-2 barg towards North and West. Pressures at external explosion sensors towards North $(6 \mathrm{~m}, 12 \mathrm{~m}$ and $24 \mathrm{~m}$ outside vent opening) and East $(48 \mathrm{~m}$ outside opening) are shown. While the nearest sensors to the North may be inside the vented flame ball and have similar characteristics as internal pressure waves (triangular shape with $100 \mathrm{~ms}$ duration), it can be seen that the blast duration of the sensor $24 \mathrm{~m}$ North is reduced to $60-70 \mathrm{~ms}$, and for the sensor $48 \mathrm{~m}$ to the West the blast pressure has the character of a shock wave.

The third tests is test 8 among the ignited jet releases from the Phase 3B experiments, this is performed with the same geometry configuration as the previous example with venting in three directions. The scenario is an $11.6 \mathrm{~kg} / \mathrm{s}$ natural gas high pressure release centrally in the module directed towards the blast wall and ignited centrally when approaching steady-state cloud size. Maximum pressures around 700 mbarg were reported towards East and West with duration 60$70 \mathrm{~ms}$, towards North, pressures around 400 mbarg with duration $100 \mathrm{~ms}$ were reported. Again near triangular external pressure curves with $100 \mathrm{~ms}$ duration are reported outside to the North $(6 \mathrm{~m}, 12 \mathrm{~m}$ and $24 \mathrm{~m}$ away), while the blast pressure $48 \mathrm{~m}$ to the East is in the process of developing into a shockwave with duration below $40 \mathrm{~ms}$.

The last example shown is from the post-Buncefield DDT test in tree congestion. In this experiment flames underwent deflagration-to-detonation transition within $10 \mathrm{~m}$ from ignition, and the rest of the $50 \mathrm{~m} \times 4 \mathrm{~m} \times 3 \mathrm{~m}$ propane cloud detonated. Internal pressures shown were recorded towards the end of the congested tree array, while the external blast pressures were $13 \mathrm{~m}$ and $37 \mathrm{~m}$ beyond the end of the gas cloud. The duration of the detonation pressure is of the order $5 \mathrm{~ms}$, while the duration increases somewhat in the far-field to $10-20 \mathrm{~ms}$.
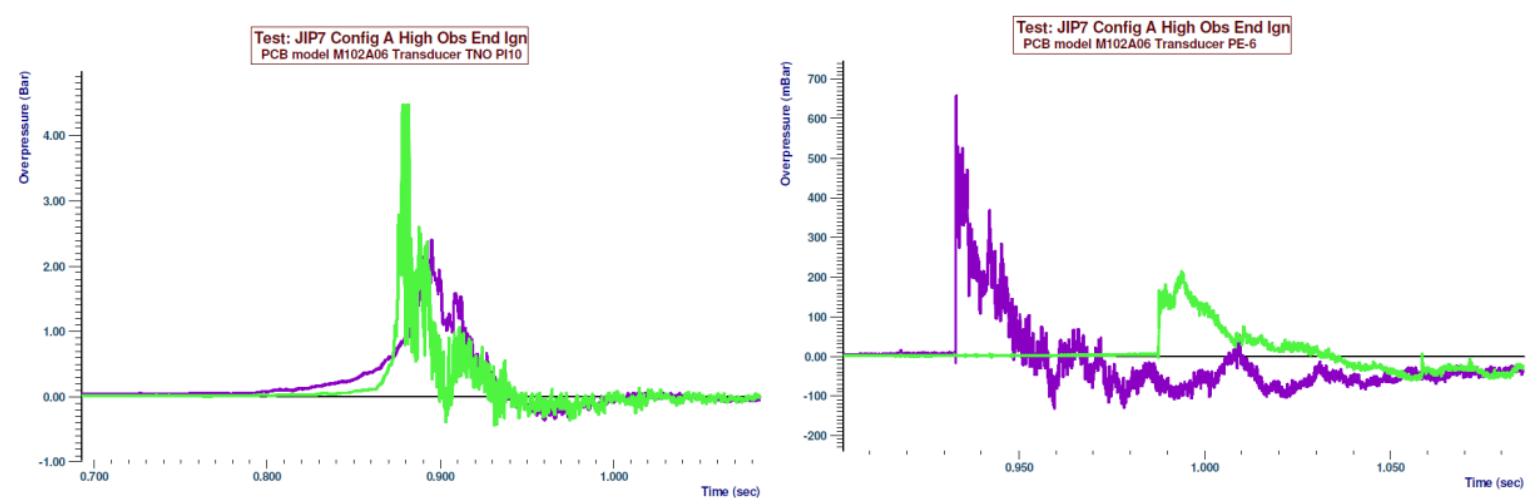

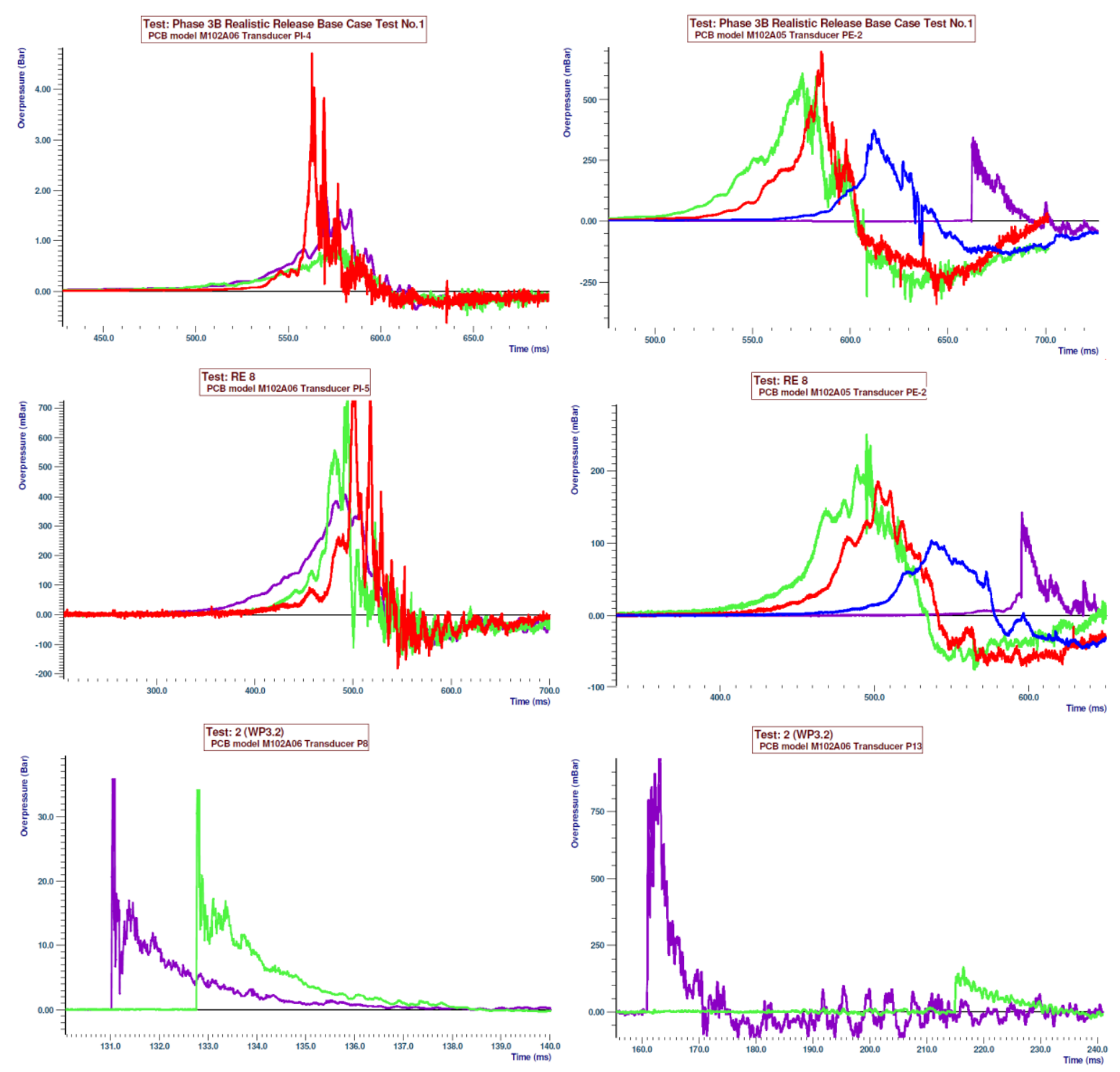

Figure 2 Examples of experimental overpressures inside flame zone (left) and blast pressures outside the explosion in the near-field/far-field (right) for same explosion scenario, BFETS-7 ( ${ }^{\text {st }}$ row), Phase 3B base case explosion test1 $\left(2^{\text {nd }}\right.$ row $)$, Phase 3B realistic release test $8\left(3^{\text {rd }}\right.$ row $)$ and Buncefield tree test 2 $\left(4^{\text {th }}\right.$ row $)$.

\section{Loading onto walls and decks}

Explosion loads onto decks, blastwalls, equipment casings/hoods and other walls are usually extracted by defining measurement panels in FLACS. Usually local panels ( $3 \mathrm{~m} \times 3 \mathrm{~m})$ are used to report localized pressures that may cause local damage, while larger global/total panels, either covering the entire deck/wall or significant fractions of these, are used to evaluate whether the structural beams can resist the accidental loads. The pressure panels will report detailed transient pressure time histories across each wall/deck element, which can be used for anything from simplified assessments against nominal wall/deck resistance to detailed non-linear finite-element analysis in which transient pressure curves from each wall element are fed into a finite element 
model to calculate whether the maximum deflection may lead to escalation. As both the walls and the panels will be moved to the nearest grid cell layer, it can be important to check that the panel actually reports pressure at the same grid layer as the wall is placed. "Inactive panels" used for pressure reporting are not physical objects, but area sensors which report the average pressures across. Parts of the panel which are not on surfaces (full porosity on both sides, for instance if there is a door through a panel) or are fully blocked on both sides, will not be included when the average pressure is estimated, thus the reporting of pressure is relatively robust.

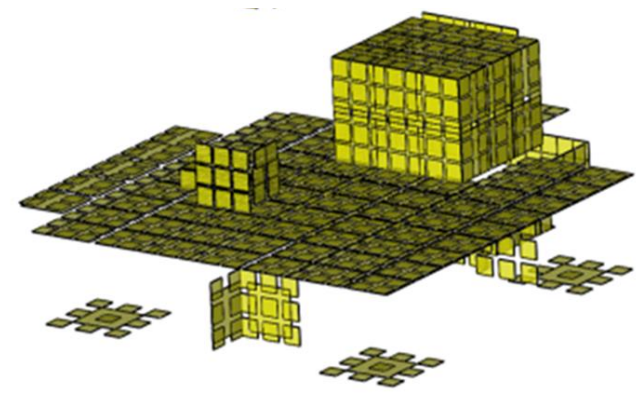

$\begin{array}{lllllllll}0.78 & 0.82 & 0.82 & 0.90 & 0.77 & 0.75 & 0.76 & 0.71 & 0.75 \\ 0.72 & 0.71 & 0.76 & 0.75 & 0.72 & 0.71 & 0.62 & 0.59 & 0.66 \\ 0.70 & 0.66 & 0.69 & 0.70 & 0.65 & 0.62 & 0.57 & 0.56 & 0.58\end{array}$

Figure 3 Example of distribution of pressure panels to report loads onto decks and walls of an oil platform (left) with a combination of $3 \mathrm{~m} \times 3 \mathrm{~m}$ panels (local), 8m $x$ 8m panels and panels covering entire walls and decks (global). The right picture shows a possible distribution of $10^{-4} /$ year local pressure loads onto a blast wall.

\section{Loading onto rectangular equipment resolved on the grid}

For equipment with dimensions larger than 2-3 grid cells (normally 1-2m) in each direction direct load measurement (DLM) is recommended. This is normally achieved by placing pressure panels onto the object and extracting maximum local loads onto a surface, which may give local damage or the differential pressure across the object, which may challenge its supports. As the directionality of explosion loads can depend on the module layout, directional forces with duration can be estimated.

\section{Loading onto cylinders and objects of other shapes partially resolved on the grid}

For objects like separators and coalescers, major structural beams and other larger objects with non-rectangular shape, it has been more of a challenge to estimate the loads from explosions properly. Best practice up to now has been to define an array of pressure point monitors around the cylindrical object and from that try to estimate maximum pressure differences, either transient or maximum value, across the object, and thereafter multiply this with a pressure distribution factor (PDF). FABIG TN-8 has proposed to use $\mathrm{PDF}=2 / \square=0.64$ for a cylindrical object, which may be appropriate. There are however challenges using this method, the first is to ensure that the pressure monitoring points are located sufficiently close to the cylindrical object to report proper stagnation pressures which is often not the case, it is also questionable to what extent a few selected points will be representative for the average load onto the cylinder, and thus there may be a significant uncertainty in the predicted loads. To conclude, the current methods applied for single cylindrical objects are cumbersome to use, and has a significant uncertainty, and for a group of objects, such an approach would not be feasible. 
In Figure 4 an improved approach for direct load measurement onto cylindrical or nonrectangular objects and groups of such objects partially resolved on the grid is illustrated. By defining an array of pressure panels going entirely through all the objects at each layer of grid cells, it is possible to report accurately the transient directional pressure loading onto the object or group of objects, without the need for pressure distribution factors or other assumptions. This method will integrate directional load contributions over the entire surface of all objects within the bundle with good precision provided each object blocks at least one grid cell. In Figure 4 an illustration of a shockwave from the left is shown after being reflected at the front of the pipe bundle, at the same time there is a chaotic pressure reflection pattern between the pipes, and the $2^{\text {nd }}$ row of pipes are further shielded by the front row. Using the traditional approach it would be very challenging to estimate loads onto the pipe bundle, or even one of the pipes. With the new proposed approach in which we define an array of pressure panels to calculate the integrated, directional load onto pipes or pipe bundles, the loads onto the pipe bundle can be estimated. In lower right plot of Figure 4 the total load on the four pipes, as well as the load on a single pipe (without the other three pipes present) estimated with the new method is shown. It can be observed that the peak load onto the pipe bundle is only $10 \%$ lower than it would be with four individual pipes not influencing each other, i.e. the shielding effect is very moderate. The duration of the load is also significantly longer for the bundle than for a single cylinder, due to a quicker equalization of pressure across one cylinder than across the bundle.

\section{Loading onto equipment not resolved on the grid}

In the introduction section an improved, proposed new method (Hansen and Johnson, 2015) was described for accurate load estimates onto objects not resolved on the grid (diameter $\sim 2$ grid cells or less). This approach takes into account both loading due to the dynamic pressure (drag) of the flow but also load contributions due to pressure differences in the flow field due to accelerated flow field around the object or pressure waves acting onto the object, ref (2).

$$
\text { Force }(\mathrm{t}) / \operatorname{Area}=\mathrm{C}_{\mathrm{d}} \mathrm{x} \operatorname{Drag}(\mathrm{t})+\operatorname{PDF} \mathrm{x}\left[\mathrm{P}_{\mathrm{s}}(\mathrm{t})-\mathrm{P}_{\mathrm{s}}(\mathrm{t}-\square \mathrm{t})\right]
$$

For box shaped object Hansen and Johnson (2015) applied the method to rectangular objects and by comparison to direct load measurements (DLM) demonstrated that transient, directional loads could be estimated with good precision if drag coefficient $\mathrm{Cd} \sim 2.0$ and $\mathrm{PDF}=1.0$ were used. A similar validation effort has not yet been performed for cylindrical objects or objects of other shapes. But provided proper directional drag coefficients and PDF are chosen, the approach should work equally well for these objects, and can easily be adapted also to estimate loads onto rotated objects not aligned to the Carthesian axes. For cylindrical objects, and some other shapes, one should be aware that the drag coefficient may be Mach- and Reynolds-number dependent. While drag coefficients of 1.2, 1.0 or even lower are frequently applied and justified by some, it is a fact that the drag coefficient of pipes may also be higher $(\mathrm{Cd} 2.0)$ in a strong explosion. Until a better understanding has been developed in this field, it is proposed to apply a dragcoefficient of 1.2 for cylindrical objects, and $\mathrm{PDF}=0.64$, and potentially even higher, $\mathrm{Cd}=2.0$, for loads in situations with Mach-numbers approaching 1.0. This will be discussed in the next chapter. 
For precise load estimates care must be taken to detect the directions of the accelerated flow or pressure waves (whose load contributions could in theory act in different directions at the same time) in order to keep track of cancelling load contributions or orientation of the loads.
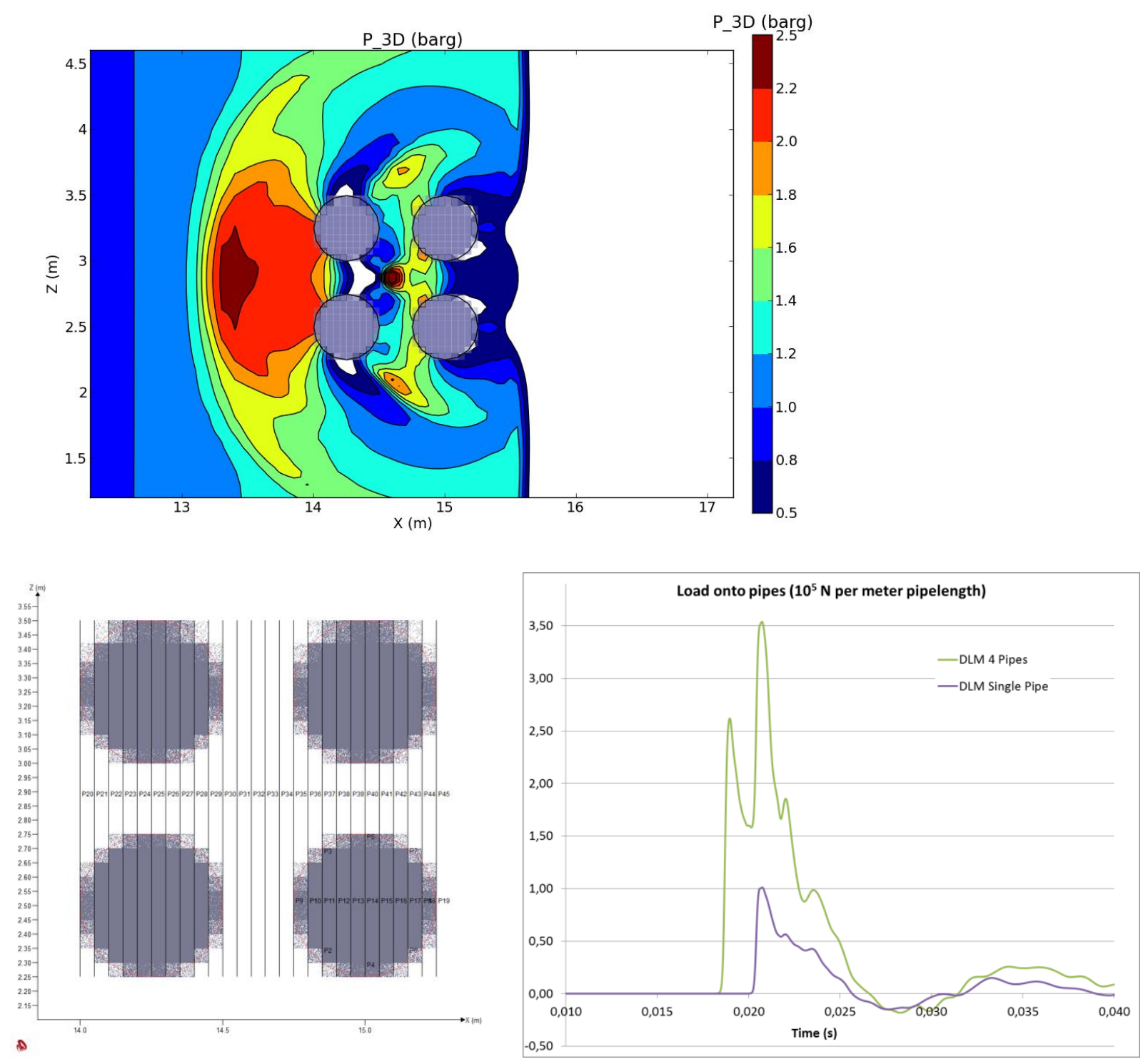

Figure 4 Illustration of method used to report accurate loads from cylindrical tanks and other non-rectangular shapes partially resolved on the grid. In the upper plot the pressure field is shown as a shockwave hits a pipebundle. By defining FLACS pressure panels through every grid plane through a cylinder or bundle (lower left), the detailed transient load received at one cylinder, or the bundle as a group of objects, can be predicted with good precision.

\section{Loading onto grated decks and porous objects}

For partially porous objects, i.e. louvered walls or grated deck areas, the methods described above will not work. While a pressure panel defined across a deck area which is e.g. $40 \%$ open and $60 \%$ plated will report a pressure load which is representative for the plated area, and ignore 
the open areas, a panel defined across a $60 \%$ area porosity grated area will instead report the average load over the entire area. The best way to report the loading onto the grated deck area will thus be to define a panel across the entire area covered by the grated deck, which is assumed to have porosity somewhat lower than the grating porosity due to beams and equipment. The load onto the deck area will then be the panel pressure multiplied by the total area (deck porosity should not be considered when estimating the total forces to the deck). If there are large H-beams below the deck receiving some of the loads, or elevated areas above the deck (e.g. skid fundaments), there may be a need to combine this panel approach with the approach discussed for objects partially resolved on the grid (as shown in Figure 4), in order to estimate the total load onto the deck.

\section{How to select drag coefficients - example from large scale explosion test}

The estimated explosion loading for small objects becomes directly proportional to the chosen drag coefficient. FABIG TN-08 guidance note recommends using conservative drag coefficients for load estimates on piping and small equipment, which means $\mathrm{Cd}=1.2$ for pipes, and likely $\mathrm{C}_{\mathrm{d}} \sim 2.0$ for rectangular profiles. Still, some standards recommend lower drag coefficients, e.g. $\mathrm{C}_{\mathrm{d}}=1.0$ for pipes (API-RP-2FB, 2006 and DNV-RP-D101, 2008), and to limit design costs it may be no surprise that many companies choose the lower values. Based on simulations of gas explosions Hansen and Johnson (2015) concluded that conservative drag coefficients $\left(\mathrm{C}_{\mathrm{d}} \sim 2.0\right.$ for box shapes) were required to obtain accurate predictions of loading, and further expecting that $\mathrm{C}_{\mathrm{d}} \sim 1.2$ would be appropriate for cylindrical objects. A validation effort for cylindrical objects similar to that performed for rectangular objects, identifying the drag coefficients required to estimate the reported DLMs using free-flow parameters (drag, pressure and density) has not yet been performed.

Steady-state flow experiments have shown that while the drag coefficient of $\mathrm{Cd}=1.2$ may be appropriate for low Re, with increasing Re (beyond $10^{5}$ ) the drag-crisis may give a narrower wake, with the result that the drag coefficient drops to less than half, before increasing again to 0.7-0.8 at $\operatorname{Re}=10^{7}$. The drag-crisis is observed for developed, steady-state flow scenarios around a single cylinder, and it is highly questionable whether this is relevant for the flow-field inside a turbulent explosion at its maximum strength. It is assumed that upstream wake effects and accelerated flow fields will prevent the developed flow situation of the drag-crisis, and therefore recommended to use conservative drag coefficients for cylinders $(\mathrm{Cd}=1.2$ and even 2.0 for $\mathrm{Ma}$ approaching 1.0). In the following a validation example will illustrate why.

\section{Drag coefficients - example case \& validation}

During the BFETS full-scale explosion experiments at Spadeadam (SCI, 1998) an instrumented cylinder was used to measure received explosion load for some of the explosion tests. The actual cylinder was a $2.0 \mathrm{~m}$ long $0.5 \mathrm{~m}$ diameter vertical pipe located at floor level within one meter of the East exit of the full-scale rig, see FLACS-model and photo in Figure 5. The cylinder was placed on top of a load cell which would report the torque along and across the axis of the module, which will be the main flow direction. In addition to the load cells at the base of the cylinder, there were also four pressure sensors at mid-height of the cylinder, which could be used to get a good estimate of the pressure load across the cylinder along and across the main flow 
direction. There were also 25 other pressure sensors inside the module which would report transient pressure.
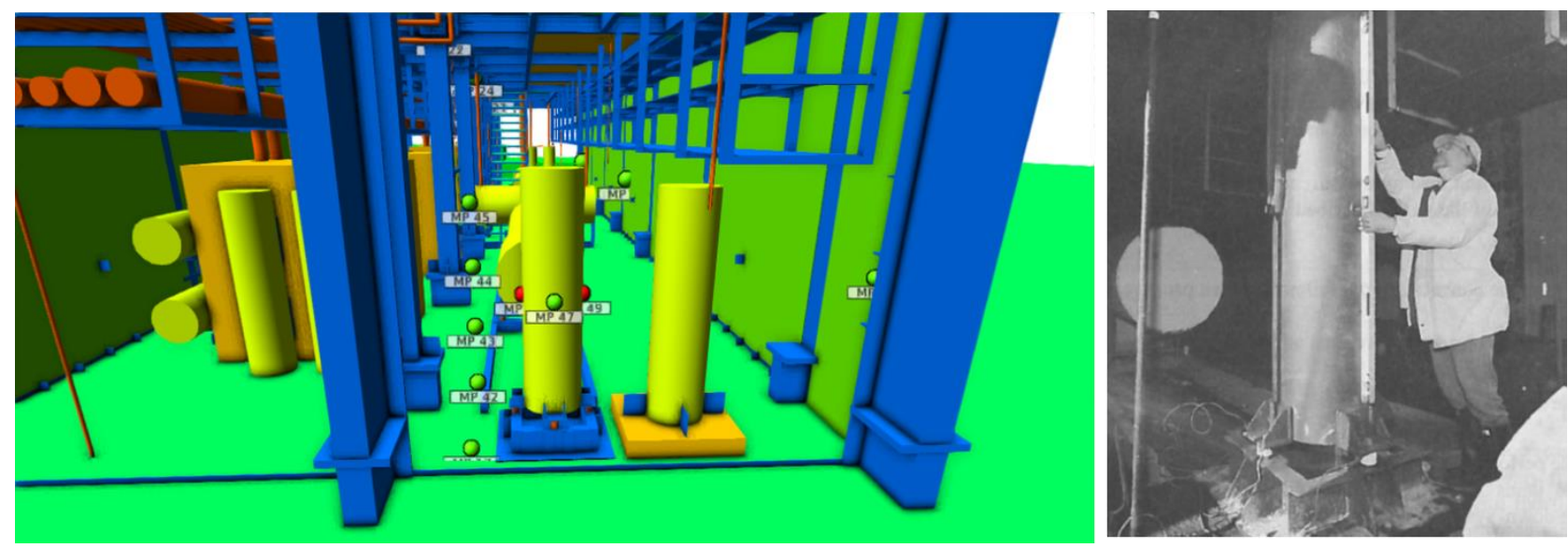

Figure 5

\section{FLACS model of BFETS module with instrumented load cell cylinder (left), and photo (SCI, 1998) of actual cylinder (right)}

The case used for this example is the BFETS test 12, which was a center ignited, slightly overstoichiometric natural gas explosion experiment in the base-case $25.6 \mathrm{~m} \times 8 \mathrm{~m} \times 8 \mathrm{~m}$ tunnel geometry with venting towards East and West. The maximum overpressures reported in this experiment were generally near 2.5 barg at the centre of the module, and around 1.0-1.5 barg near the ends, with the exception of one sensor near West exit (load cell was at East) which reported a pressure peak around 3.1 barg with a short duration. In the left plot of Figure 6 maximum pressures at two sensors at the center of the module is shown as reported in the experiment (green) and as simulated with FLACS using coarse (1.0m-blue) and fine (0.5m-red) grid resolution. The predicted overpressure at the ground next to the instrumented cylinder is also shown for all three cases. In general the pressure predictions seem very good for most of the 25 locations, both for the fine grid and the coarse grid simulations, however it can be seen that the pressure next to the cylinder is somewhat high (almost 2.0 barg vs 1.5 bar) for the $0.5 \mathrm{~m}$ grid. In the right plot of Figure 6 the flow Mach number next to the cylinder can be seen at four different heights, peaking at $\mathrm{Ma}=0.6$ prior to flame arrival, and between $\mathrm{Ma}=0.7$ (lower part of cylinder) and $\mathrm{Ma}=0.9$ (upper part of cylinder) after the flame has passed. Due to the higher temperature in the flame zone, the actual flow velocity is around 4 times higher after the flame has passed.

With a grid resolution of 0.5 or $1.0 \mathrm{~m}$ is it not feasible to extract any reliable stagnation pressures onto the load cylinder, however, by refining the grid to $0.10 \mathrm{~m}$ locally around the cylinder, it is possible to extract pressures around the cylinder with reasonable precision. This approach is mentioned in (Lloyd's Register, 2015), but requires a special setting to make the time stepping routine in FLACS ignore the grid refinement to deliver reasonable predictions, and the approach is not practical to use for more comprehensive studies including a large number of simulations. In Figure 7 the differential pressures at mid-height across the cylinder in the direction of the module axis can be seen for the experiment (red) and for the two FLACS simulations with $0.5 \mathrm{~m}$ (purple) and 1.0m (green) base grid resolution. The first pressure peak (prior to flame arrival) reached 0.75 barg in the simulations, however, only 0.5 barg in the experiment while the second 
and main peak reached around 1.8 barg in the experiment and around 1.5 barg in the simulations. Except for some mismatch in the shape of the first peak, and some noise and termination on the reported differential pressure peak from experiment, the shape and duration of the main differential pressure peak corresponds very well to the simulations. It should be observed that the duration of the main peak seems close to $100 \mathrm{~ms}$. In the right plot of Figure 7 the maximum pressures reported at object surfaces can be seen for the fine grid simulation $(0.5 \mathrm{~m}$ base grid with refinement to $0.10 \mathrm{~m})$.
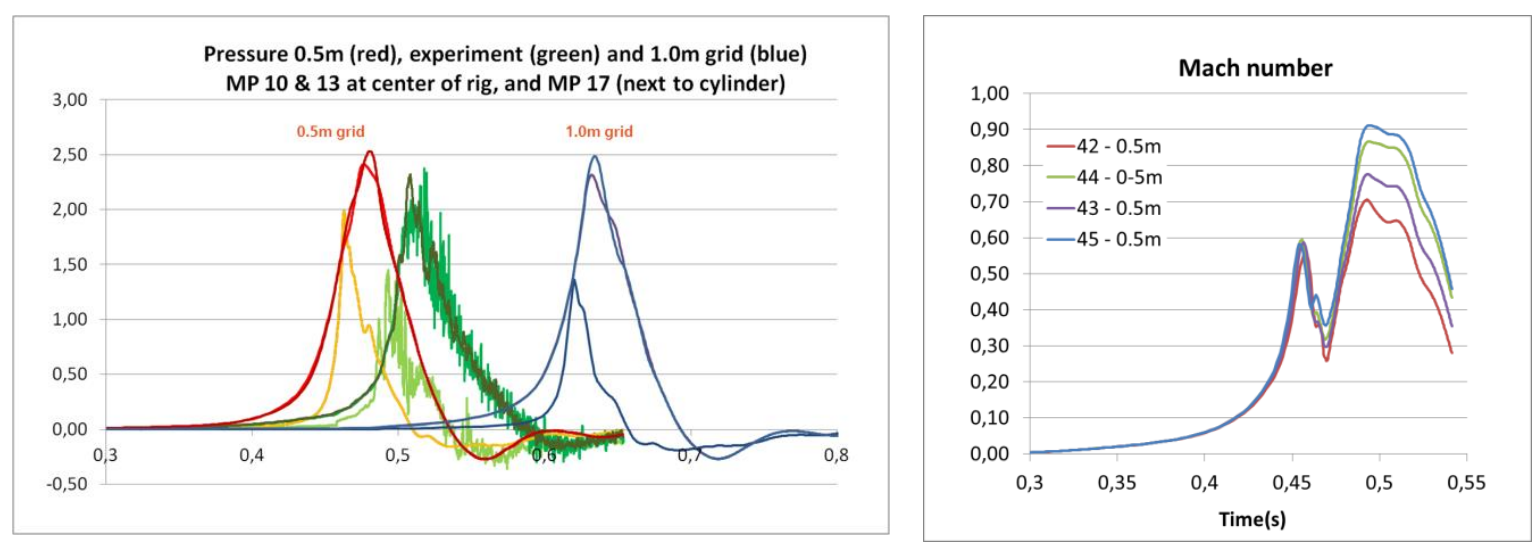

Figure 6 Simulated pressure curves (near centre of module) with $0.5 \mathrm{~m}$ grid and $1.0 \mathrm{~m}$ grid compared to BFETS 12 experiment (left), predicted Ma-numbers in the flowfield next to the instrumented cylinder (right) using $0.5 \mathrm{~m}$ grid resolution.

The comparison of pressure curves from simulations and experiment at various locations inside the module, and the differential pressure across the instrumented cylinder, confirms that the simulations can reproduce the dynamics of the explosion test with good precision. It is therefore reason to believe also that the Mach-numbers reported, as well as dynamic pressures (Drag) presented in Figure 8 at different elevations next to the pipe are predicted with good accuracy.

In Figure 8 to the right the reported load cell torque (Force $\mathrm{x}$ length) received at the cylinder is plotted. As the distance between the load cells is $0.67 \mathrm{~m}$ this corresponds to a maximum average force per area received over the projected cylinder area $\left(0.5 \mathrm{~m} \times 2.0 \mathrm{~m}=1 \mathrm{~m}^{2}\right)$ of $120 \mathrm{kPa}$, while from Figure 7 a maximum pressure difference $\square \mathrm{P}$ across the cylinder at mid-height was reported to be around 1.8 bar $(180 \mathrm{kPa})$, while Figure 8 shows a maximum drag load around $60 \mathrm{kPa}$. For the moment of maximum load we may then coarsely estimate

$$
\begin{aligned}
& \mathrm{Cd}=\mathrm{Load} / \mathrm{Drag} \sim 120 \mathrm{kPa} / 60 \mathrm{kPa}=2.0 \\
& \mathrm{PDF}=\mathrm{Load} / \mathrm{DP} \sim 120 \mathrm{kPa} / 180 \mathrm{kPa}=0.67
\end{aligned}
$$

which confirms that the proposed $\mathrm{PDF}=2 / \square=0.64$ from FABIG TN-08 seems reasonable.

In the right plot of Figure 8 the load cell received torque is plotted together with an estimated torque resulting from the drag forces for different heights above the cylinder base for the full duration of the explosion. In order for the received and estimated torques to match, a drag 
coefficient of around 0.6 would be appropriate prior to flame arrival (first peak of load curve), however after flame arrival a drag coefficient as high as 2.0 seems to be required, as estimated above. Thus it seems as if very high drag coefficients for pipes can be seen already at drag values of 50-60 $\mathrm{kPa}$ and for Mach numbers around 0.8. Comparing the load cell reported torque with the estimated load due to drag forces in Figure 8 indicates that the load cell cylinder enter oscillations with a period around $50 \mathrm{~ms}$ after reaching the maximum displacement.
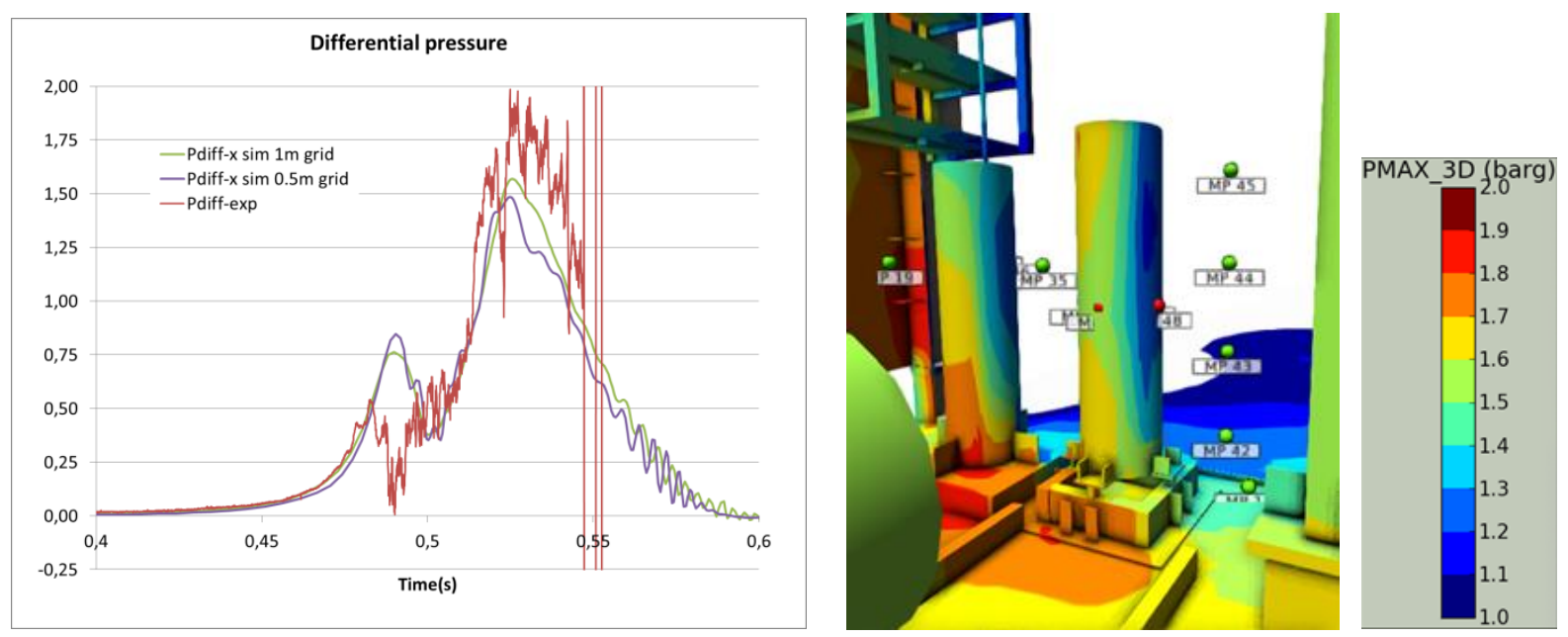

Figure 7 Differential pressure across load cylinder from pressure sensors mounted at front and back. Simulations using local grid refinement and $1.0 \mathrm{~m}$ and $0.5 \mathrm{~m}$ base grid size versus experimental measurement (left), maximum pressure field (right)

To conclude this section, this example demonstrates that cylinder drag coefficients may be both lower ( 0.6 prior to flame arrival, at Ma 0.6) and higher (2.0 after flame arrival at Ma 0.8) than typically used drag coefficients (1.2 or 1.0) used for piping design. While more relevant cases should be studied before concluding, industry should ensure to use sufficiently conservative drag coefficients for design.

\section{Response - filtering loads using Dynamic Load/Amplification Factor (DLF/DAF)}

The loading from an explosion scenario will be a transiently changing pressure distribution acting onto all objects, walls and decks. For a given object this can give deformation of the surface (local pressures) or threaten the integrity (global or differential pressures). For blast walls, structures or piping systems this may give deflections or deformations and if the deformations are significant it may lead to failure and loss of containment of hydrocarbon piping or equipment, and a potentially uncontrolled escalation.

The degree of damage depends on the magnitude of the overpressure or pressure difference, the area this is acting upon, and the duration of the pressure loads (or integrated pressure impulse). While all the necessary detailed information may be available from a CFD explosion study, it is common that the load is simplified into one single number, the maximum overpressure, or at best a maximum overpressure averaged across a smaller or larger surface, while the time dependency is often ignored. 

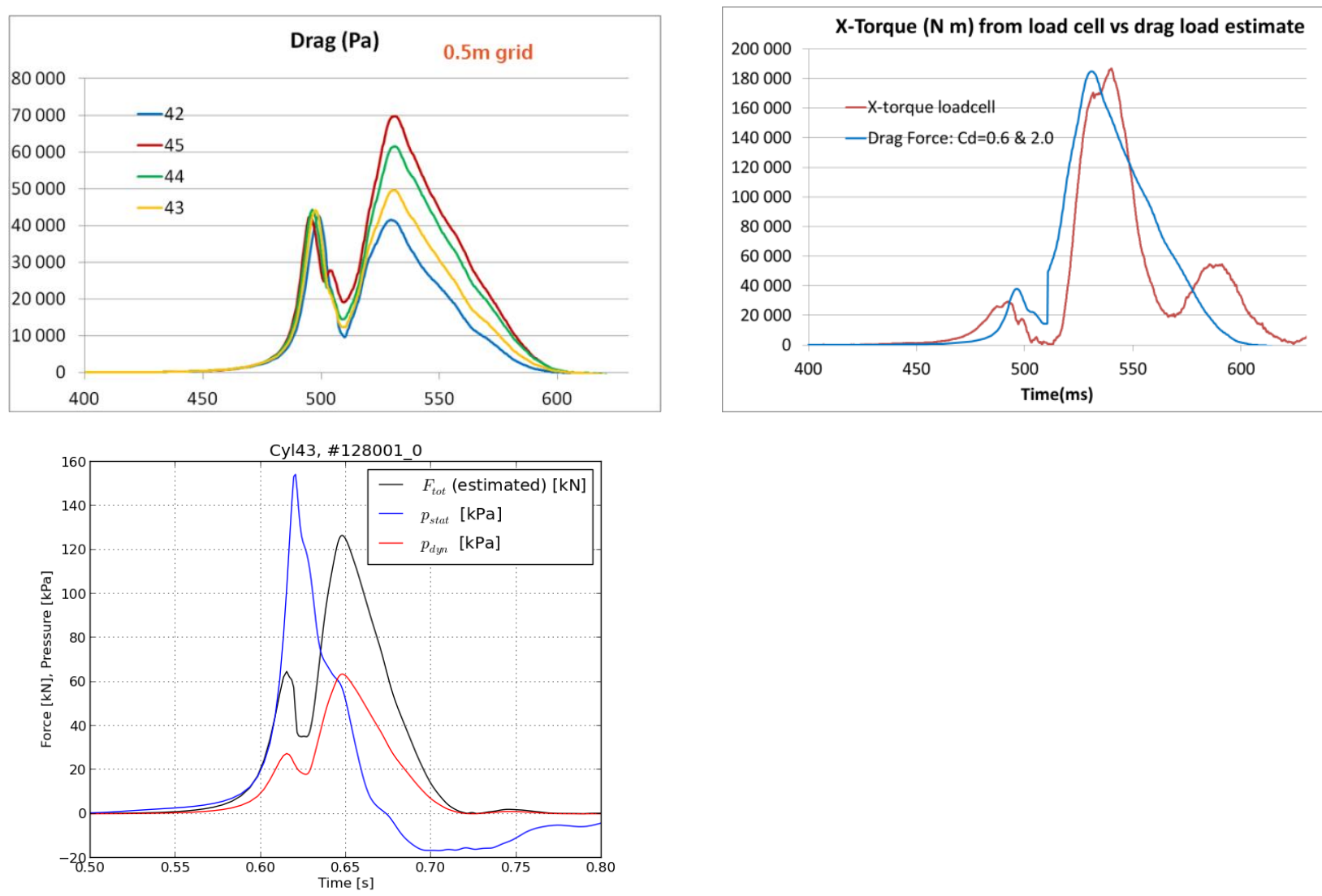

Figure 8 Predicted drag around cylinder (upper left), and load cell output versus force predicted based on drag curves using drag coefficient $\mathrm{Cd}=0.6$ prior to flame arrival and $\mathrm{Cd}=\mathbf{2 . 0}$ after flame arrival (upper right). In the lower picture the estimated received loading $\mathrm{kN}$ (=kPa over $1 \mathrm{~m}^{2}$ projected area) onto the cylinder (black curve assuming $\mathrm{Cd}=\mathbf{2 . 0}$ ) is shown together with the static side-on pressure (blue) and drag pressure (red curve) using the methodology of Hansen and Johnson (2015)

The duration of pressure loads, in particularly some distance outside the explosion, will tend to be short, often only 10-30 ms. For heavy structures e.g. blast walls or separators, this may be much too short to accelerate the structure, and such short loads will barely be felt by the objects. In a probabilistic study consisting of several hundred different explosion scenarios, the received loads onto an object may partly be due to explosions surrounding the object with load duration 100-200 ms and partly due to explosions some distance away with shorter load duration onto the target. In a probabilistic assessment such loads are normally sorted after increasing severity into a load frequency exceedance curve. For simplicity the maximum overpressure is used to rank the severity, even if some of the high pressure loads have a too short duration to be of any threat to the structure. From the probabilistic assessment a pressure with e.g. a $10^{-4} /$ year return frequency for a given object or worst-case across a group of object, would be selected as dimensioning. If a static design would be applied, this estimated overpressure would be multiplied by a worst-case dynamic amplification factor (DAF), typically of 1.5 for a triangular load pulse shape, and the 
structure is thereafter designed for this static strength. Such an approach may be much too conservative, since some of the loads classified as severe due to high maximum pressure would actually be less of a problem due to the short duration of pressure pulse.

With all the information available from an explosion study, it is possible to take the load duration into account. By applying a dynamic load factor (DLF) to estimate a characteristic static load for each pressure curve on a target, a more accurate severity scaling may be obtained. In this example the elastic response load function in Figure 9 is applied (FABIG, TN-08). For a load duration $t_{d} / T$, between 0.5 and 1.5 (dynamic regime), the load will be multiplied by a factor of 1.2 to 1.6, while for shorter load durations (impulsive regime) the severity of the load will be proportional to its impulse, not its maximum pressure. For loads with a longer duration than 1.5 times the eigenperiod (quasistatic regime) the load should be multiplied by a factor around 1.01.2. With this approach a more accurate ranking of severity is achieved.

In practice DAF and DLF are the same and in (HSE, 1999) both are defined to be "the ratio of the deflection at any time to the deflection which would have resulted from a static application of the load, which is used in specifying the load time variation".
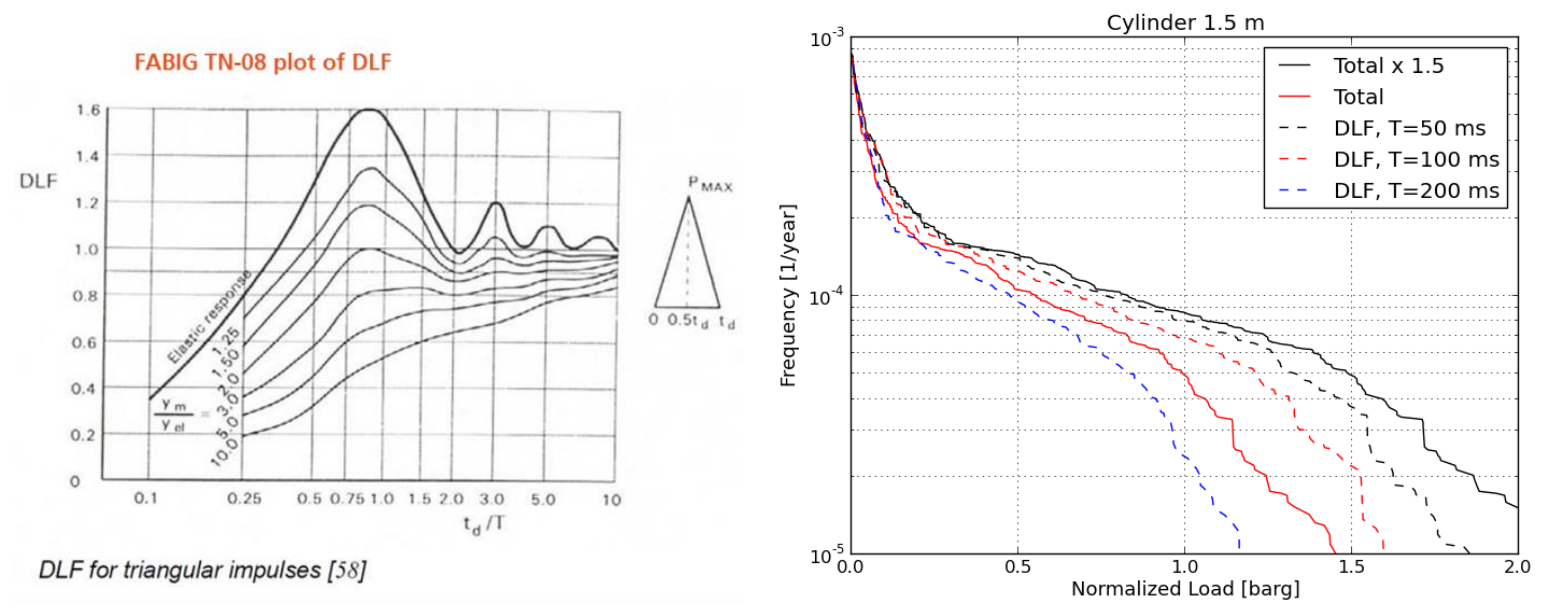

Figure 9 If a static design is applied the predicted maximum loads are often multiplied by a dynamic amplification factor of 1.5 . In reality this factor will depend on the eigenperiod of the object (see graph from FABIG TN-08, left). If this is taken into account in the assessment, and the predicted load is scaled, the load exceedance curves could be adjusted based on the eigenfrequency of the objects.

When applying the DLF of Figure 9 (left), modified load frequency exceedance curves can be obtained as seen in Figure 9 (right plot), which shows the maximum load onto a $1.5 \mathrm{~m}$ diameter object located anywhere, with any orientation inside a module. More than 500 explosion scenarios, each with a frequency of occurrence, have been used to generate each of these curves. While the red curve is the typical unfiltered pressure exceedance curve resulting from typical explosion studies, the black curve will be the same data after multiplied by a dynamic amplification factor (DAF) of 1.5. Then there are three more curves using the DLF-filters assuming eigenperiods of 50,100 and $200 \mathrm{~ms}$ of the objects. If a design frequency of $5 \times 10^{-}$ 
5/year is applied, this would give required design strength of 1.5 bar without considering the eigenperiod. By assuming 50, 100 or $200 \mathrm{~ms}$ eigenperiod of the structures, this would reduce the required static design strength significantly, to $1.3,1.2$ and 0.8 bar respectively. And if also the size, orientation and position of the critical equipment would be considered, a significantly lower required design load might be estimated.

\section{DAL-Area differentiation}

One of the main purposes of an explosion study during design phase is to establish the design strength of the facility. Depending on the philosophy this can either be designed to withstand a credible or realistic worst-case incident, or more commonly for offshore facilities, to survive accidental explosions for 10,000 years or more. To design for any credible scenario can be challenging. Sometimes credible is defined by the size of the gas release, only considering the $90 \%$ lower hole sizes, but since the severity of an explosion scenario depends on so many other factors, e.g. combination of release location, direction, wind speed and direction, ignition location and time, and the worst-case consequences for different targets will be seen for different scenarios, it is actually quite challenging for a safety consultant to perform a "credible worstcase" study properly. If "non-credible" instead would be defined to be the most severe scenarios with a return frequency less than every 10,000 years, these two approaches would converge.

A typical approach when defining dimensional accidental loads (DimAL) from an explosion study, for instance on an oil platform, is to define a number of safety critical functions or elements, e.g. main support frame, blast walls or decks between processing areas and safe utility areas on an oil platform, or escape route impairment. A main job will then be to define the necessary dimensioning strength for blast walls and decks to maintain their function separating the different areas, or proper design strength for hydrocarbon piping, so these will avoid rupture and severe fire escalation that may impair escape routes. Safety systems like deluge piping should also be designed sufficiently strong, the same applies for any piece of equipment to prevent it from becoming a projectile that could contribute to uncontrolled escalation in the event of a significant explosion. Since defined safety critical functions or barriers can be impaired in different ways, there is often a significant room for optimization when defining dimensioning accidental loads. A weak design of piping will lead to a higher frequency of fire, which may require better protection with passive fire protection or more focus on protection of escape routes from smoke. The division between process or drilling areas and safe areas (utility, TR) may consist of several different wall elements, and the tolerable frequency of escalation (e.g. $10^{-4} / \mathrm{y}$ ) can be distributed between these, and the consultant can choose to apply comparable design strength for all wall elements, so that the main risk for escalation is found in the areas with most frequent strong explosions, or alternatively a stronger design will be applied here, so that the risk for failure is more evenly distributed among the various areas.

Once the consultant has proposed dimensioning accidental loads the engineering company and the asset owner will consider this input, and potential uncertainties, and thereafter choose design accidental loads (DeAL). These must be selected so that the structures can withstand equally high loads or higher loads than specified in the DimAL, to account for uncertainties and give additional robustness of the facility. 
For onshore siting studies the design strength of control rooms, and other buildings or areas where people are working or sheltering people, may be more in focus.

To establish proper dimensioning loads based on a probabilistic study it is important to have modeled a significant number of scenarios, with as representative as possible distribution of scenarios and frequencies. In addition it is important to have clear tolerance criteria for the targets, either individual targets like main blast wall or TR, or combination of targets like any hydrocarbon carrying pipe or equipment inside the module that may rupture and lead to escalated fire.

For individual targets it may be important to check that frequency of scenarios that may give loads beyond design strength must be lower than tolerance criteria, depending on the design, there maybe criteria for localized loads/damage (maximum pressure at any local panel) and loads acting onto the entire structure (global panels). While it is common to develop pressure frequency exceedance curves for one wall at a time based on all simulated scenarios that may contribute to failure, a different approach will be required to estimate the failure properly, since some explosion scenarios may give failure on several walls, another group of scenarios may impair e.g. the West wall and finally a third group of scenarios may impair the North or South walls. For a consistent handling there may thus be a need to calculate the potential for impairment scenario by scenario on either of the walls, and to complicate the evaluation, the different walls may also have a different design strength.

Similarly, if the strength of the blast wall local panels is verified, one should not evaluate the frequency of each particular panel to fail, but the frequency for at least one panel to fail the criteria. With a good communication between structural disciplines and the safety consultant, it may be possible to go even more in detail regarding the failure criteria, e.g. considering not only the maximum magnitude of the load, but also the duration.

When establishing the dimensioning loads for hydrocarbon piping and equipment one can often assume that wherever there is a high drag load, there will be a hydrocarbon pipe or equipment that may break and lead to fires. Thus, the frequency of rupture of a given pipe/segment is therefore not particularly interesting, but instead the frequency that one or more pipes or segments anywhere in the process area will rupture from explosion events should be established. For this reason it is common to define one dimensioning drag load across the entire module area, and similarly one load for each object size for intermediate objects.

For large process areas, which includes areas of different character both regarding leak sources and degree of congestion/confinement, there may be systematic variation in loads across the module. In the inner part of the module, both the magnitude and duration of loads may be higher than in the less confined outskirts of the module. For such situations it may be a waste of steel and money to apply the same dimensioning accidental loads everywhere. In Figure 10, upper picture, an illustration shows a process module which has been split into 10 different regions, and for each region the frequency for exceeding a typical design drag load has been calculated. The plot clearly shows that the explosion load severity is significantly higher in the central parts of the module close to the blast wall. In order to avoid overdesign a differentiated dimensioning drag load across the module was proposed, with the highest dimensioning load in the most 
exposed areas of the module, $20 \%$ lower resistance in the corners of the module, and $40 \%$ lower resistance in the outskirts (cantilevers), see illustration in the lower part of Figure 10. By assessing all the simulated scenarios against failure, it was found that this modification of proposed dimensioning load led to only a marginal increase of the required maximum dimensioning drag load, while a weaker design would be acceptable in large parts of the module.

If the detailed location and orientation of larger hydrocarbon process equipment and piping is known, such an assessment could easily be combined with an assessment of larger vessels, separators, knock-out drum and more, in which directional loads are evaluated for the larger equipment

Possibilities are many, and there is a lot of information available from an extensive explosion modeling study which could be of great value to the structural assessment study. The more information that is utilized in the structural assessment, the better job can be done. Typically the more simplified the output from the explosion study to the structural assessment become, the more conservatism will be required in the design.
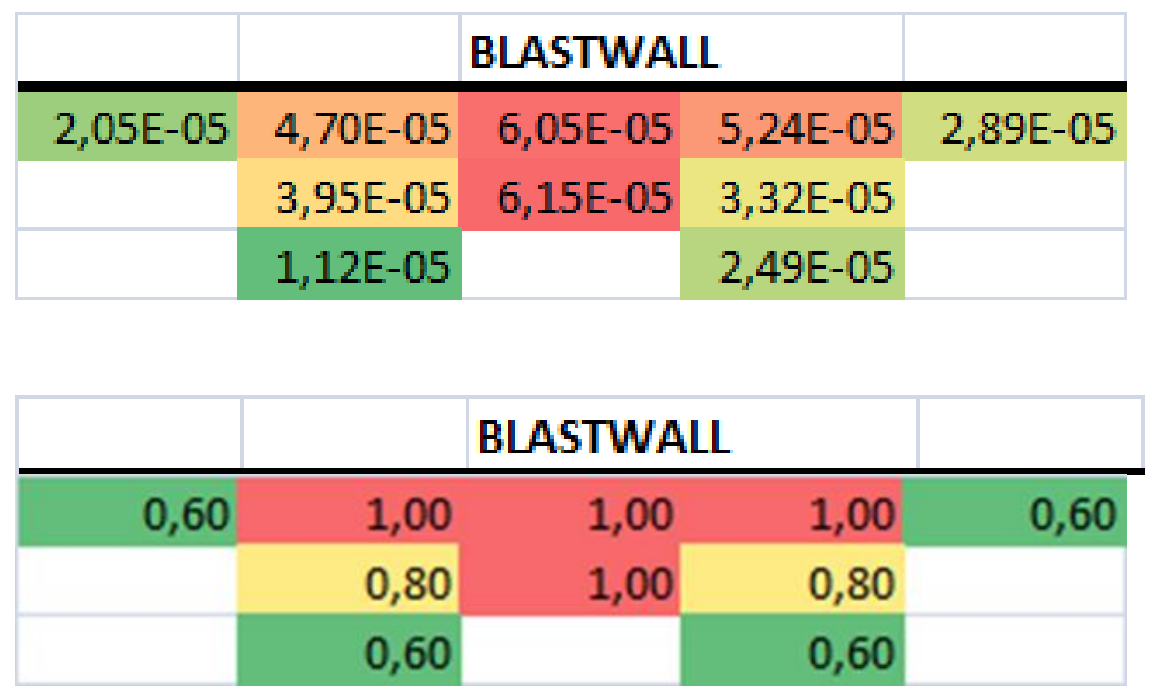

Figure 10 Illustration of area differentiation of proposed dimensioning drag loads onto piping. In the upper plot the annual frequency of exceeding a typical dimensioning load (=failure) is evaluated by area. Based on this it is proposed to keep a robust design in central areas of the module near the blast wall, while the dimensioning loads are proposed reduced towards the periphery of the module, see proposed load reduction factors by area in the lower plot.

\section{$7 \quad$ Discussion and conclusion}

The extraction of explosion loads onto equipment from CFD explosion calculations is done every day by safety consultants. The guidance and understanding on how this should be done is often weak, and very conservative or non-conservative results may result. In this paper several 
aspects around extracting explosion loads have been discussed. First the need for accurate CFD calculations and a representative scenario selection is discussed. Thereafter shape and duration of explosion loads, as well as optimal ways for extracting loads on various types of targets are handled. Among the novel suggestions in this paper is how detailed loads may be extracted for cylindrical vessels, as well as pipe bundles, by the use of multiple pressure panels. A recently developed approach to predict detailed transient, directional loads onto small and medium sized equipment is also further discussed. The choice of drag coefficients is discussed, and a full scale explosion experiment in which received loading was reported is simulated for validation and illustration purposes. This both confirmed that the pressure distribution function, $\mathrm{PDF}=2 / \square=0.64$, proposed by FABIG TN-08 seems reasonable, but also that for explosions of significant strength conservative drag coefficients should be applied for pipes. For the experiment simulated a drag coefficient as high as $\mathrm{Cd}=2.0$ was necessary to estimate loads properly. The paper also discusses challenges with linearizing the load severity into maximum pressure only, and illustrated the potential benefits if a dynamic load function filter, taking into account duration of load, could be applied when linearizing the load severity. Finally there is a discussion on establishing dimensioning accidental loads from an explosion study, in which an example is shown where differentiated design strength for different parts of a module is proposed. To conclude, the better the precision in the predicted accidental loads is, and the more information that can be utilized in the structural assessment, the more optimal and cost-efficient it is possible to design.

\section{References}

API-RP-2FB (2006), Recommended Practice for the Design of Offshore Facilities against Fire and Blast Loading, the American Petroleum Institute

API-RP 752 (2009): Management of Hazards Associated with Location of Process Plant Permanent Buildings, the American Petroleum Institute

DNV RP-D101 (2008), Structural analysis of piping systems, Det Norske Veritas, October 2008

FABIG TN-08, Protection of Piping Systems Subject to Fires and Explosions, The Steel Construction Institute, Silwood Park, Ascot, Berkshire, SL5 7QN, United Kingdom

FLACS 10.4 Users Manual (2015), www.gexcon.com

Hansen, O. R., Talberg, O., \& Bakke, J. R. (1999). CFD-based methodology for quantitative gas explosion risk assessment in congested process areas: examples and validation status. In Int. Conf. and Workshop on Modelling the Consequences of Accidental Releases of Hazardous Materials. 28 Sept-1 Oct 1999 (pp. 457-477). San Francisco, California: AIChE, CCPS.

Hansen O.R., F. Gavelli, S.G. Davis, and P. Middha (2013), Equivalent cloud methods used for explosion risk and consequence studies, J Loss Prev Process Ind 26 (2013), 511-527. 
Hansen, O.R., Kjellander, M.T., Martini, R. and Pappas, J.A. (2014), Estimation of explosion loading on equipment from CFD simulations, proceedings 17th Annual Int. Symp., Mary K O'Connor Process Safety Center, College Station Oct 28-30, 2014, pp 1042-1069

Hansen, O.R., Storvik, I. \& van Wingerden, K. (1999). Validation of CFD-models for gas explosions, FLACS is used as example. Model description, experiences and recommendations for model evaluation. Presented at the 'European meeting on chemical Industry and Environment', 1-3 September 1999, Krackow, Poland: 16pp.

Hansen, O.R. and Johnson, D.M. (2015), Improved far-field blast predictions from fast deflagrations, DDTs and detonations of vapour clouds using FLACS CFD, Journal of Loss Prevention in the Process Industries, 35 pp 293-316, May 2015.

HSE, 1999, Review of Analysis of Explosion Response, Offshore Technology Report -OTO 98174, UK Health and Safety Executive, Bootle, Merseyside, L20 3DL, UK

ISO 19901-3 (2010) Petroleum and natural gas industries - Specific requirements for offshore structures - Part 3: Topsides structure, the Int. Org. for Standardization

Lloyd's Register, 2015, Guidance Notes for the Calculation of Probabilistic Explosion Loads, issued February 2015, Lloyd's Register EMEA, 71 Fenchurch Str, London EC3M 4BS, UK

NORSOK Z-013, (2010). Risk and emergency preparedness analysis. Norsok standard. Available from Standard Norge, Postboks 242, N-1326 Lysaker, Norway.

Sand, I.Ø. (1999). Received loading test cases. Fire and Blast Information Group (FABIG) Technical Newsletter, Issue 24, R347: 14-18

SCI (1998), Blast and Fire Engineering for Topside Structures, Phase 2, SCI publication number 253, The Steel Construction Institute, Silwood Park, Ascot, Berkshire SL5 7QN, UK 